\title{
La lectura crítica en Educación Básica Secundaria y Media: la voz de los docentes*
}

\author{
GLORIA SMITH AVENDAÑO DE BARÓN** \\ gloriaesmid@gmail.com
}

Recepción: 18 de enero de 2016

Aprobación: 10 de marzo de 2016

Forma de citar este artículo: Avendaño de Barón, G.S. (2016). La lectura crítica en Educación Básica Secundaria y Media: la voz de los docentes. Cuadernos de Lingüística Hispánica, (28), 207-232. doi: http://dx.doi.org/10.19053/0121053X.4916

* Artículo de investigación científica; se deriva de un proyecto realizado en el grupo de investigación GIESCAH, clasificado en categoría B por Colciencias, Colombia.

** Doctora en Filología Española, Magíster en Lingüística Hispánica y Especialista en Literatura y Semiótica. Docente del Doctorado en Lenguaje y Cultura y asesora de Práctica Pedagógica Investigativa de Profundización, Universidad Pedagógica y Tecnológica de Colombia, Colombia. 


\title{
Resumen
}

Este artículo presenta los resultados de una investigación cuyo objetivo fue explorar lo que saben los docentes del área de Humanidades y Lengua Castellana sobre la lectura crítica, con el fin de analizar e interpretar esos saberes y aportar algunas reflexiones al respecto. El proyecto se desarrolló en una institución pública colombiana con una muestra de 10 profesores de Educación Básica Secundaria y Media, y la información se recogió a través de encuesta con pregunta de final abierto. Los resultados revelaron: predominio de conceptualizaciones parciales y desenfocadas de ese tipo de lectura, se alude o bien a prácticas interpretativas o bien a las argumentativas y se excluye los procesos reflexivos, evaluativos, críticos y escriturales derivados; preponderancia de los enfoques lingüístico y psicolingüístico frente al sociocultural; desarrollo de talleres tomados del libro de texto como estrategia para abordar la lectura; atribución a la actitud y al desempeño de los estudiantes como dificultades para trabajar la lectura crítica; y la necesidad declarada de mejorar las prácticas didácticas para impulsarla. De la investigación se concluyó que los docentes requieren cualificación teórica y pedagógica en el campo objeto de este estudio.

Palabras clave: lectura crítica, escritura, pedagogía crítica, transposición didáctica.

\section{Critical Reading in Middle and High School: Teacher's Voices}

\begin{abstract}
This article presents the results of a research project aimed at exploring Humanities and Spanish Language teachers' knowledge regarding critical reading, in order to analyze and interpret this knowledge and invite reflection. The project was developed in a Colombian public education institution with a sample of 10 Middle and High School teachers, and the information was collected through a survey of open ended questions. The results prevailingly revealed partial and unfocused conceptualizations of this type of reading, alluding either to interpretative or argumentative practices, and excluding derived reflexive evaluation, critical and writing processes; prevalence of linguistic and psycholinguistic focus, over a sociocultural one, development of workshops extracted from textbooks as reading strategy, reference to student attitudes and development as dificulties in working with critical reading, and the declared necessity to improve didactic practices in the promotion of this skill. It was concluded that teachers require theoretical and pedagogical qualification in this field.
\end{abstract}

Key words: critical reading, writing, critical pedagogy, didactic transposition. 


\section{La Lecture critique au collège: la voix des enseignants}

\section{Résumé}

Cet article présente les résultats d'une recherche dont l'objectif a été celui d'explorer ce que les enseignants savent sur le domaine Humanités et Langue Castillane sur la lecture critique, ayant comme but analyser et interpréter ces savoirs-là et en apporter quelques réflexions là-dessus. Le projet s'est développé dans une institution publique colombienne, avec un échantillon de 10 professeurs de collège; et l'information a été collectée à travers une enquête ayant une question ouverte. Les résultats ont révélé: prédominance de conceptualisation partielles et déviées de ce type de lecture; on fait référence aux pratiques soit interprétatives, soit argumentatives et on exclut les processus réflexifs, évaluatifs, critiques et scripturales dérivés; prépondérance des approches linguistique et psycholinguistique face au socioculturel; développement d'ateliers pris du livre guide en tant que stratégie pour aborder la lecture; attribution à l'attitude et à l'accomplissement des apprenants en tant que difficultés pour travailler la lecture critique ; et le besoin d'améliorer les pratiques didactiques pour la pousser. De la recherche, on a conclu que les apprenants requièrent une formation théorique et pédagogique dans le domaine objet de cette étude.

Mots clés: lecture critique, écriture, pédagogie critique, transposition didactique.

\section{A Leitura crítica na Educação Básica Secundária e no Ensino Médio: a voz dos docentes}

\section{Resumo}

Este artigo apresenta os resultados de uma pesquisa cujo objetivo foi explorar o que sabem os docentes da área de Humanidades e Língua Castelhana sobre a leitura crítica, com o fim de analisar e interpretar esses saberes e aportar algumas reflexões a respeito. 0 projeto se desenvolveu em uma Instituição pública colombiana com uma amostra de 10 professores da Educação Básica Secundária e do Ensino Médio, e a informação se recolheu através de inquérito por sondagem com perguntas de final aberto. Os resultados revelaram: predomínio de conceptualizações parciais e desfocadas desse tipo de leitura, que se refere às práticas interpretativas ou às argumentativas e se exclui os processos reflexivos, avaliativos, críticos e escriturais derivados; preponderância dos enfoques linguístico e psicolinguístico frente ao sociocultural; desenvolvimento de oficinas tomados do livro de texto como estratégia para abordar a leitura; atribuição à atitude e ao desempenho dos 
estudantes como dificuldades para trabalhar a leitura crítica; e a necessidade declarada de melhorar as práticas didáticas para incentivá-la. Da pesquisa se concluiu que os docentes requerem qualificação teórica e pedagógica no campo objeto deste estudo.

Palavras chave: leitura crítica, escritura, pedagogia crítica, transposição didática. 


\section{Introducción}

Los procesos educativos están siendo redireccionados en muchos países, entre ellos Colombia, que desde el año 2000, a través del Ministerio de Educación Nacional (MEN), ha pregonado una pedagogía por competencias y no solamente por contenidos o temas, pero ¿Qué implica una formación por competencias? Respondemos, someramente, que ella demanda un proceso integrador, pues aglutina distintas acciones pedagógicas, entre otras: abordar conocimientos disciplinares; desarrollar capacidades, aptitudes y habilidades; articular la teoría a la práctica y promover actitudes y valores en el estudiante para que actúe en el seno de una sociedad. Entonces, esta formación integrada le permite "saber hacer" con un conocimiento ya interiorizado, aplicarlo en actividades concretas y en la solución de problemas diversos, utilizarlo en situaciones específicas de la vida y convivir en armonía con los demás. Respecto de las competencias de lenguaje, los contenidos de Lingüística (Gramática, Fonética, Morfología, Sintaxis, Semántica y Pragmática), de Literatura, de Semiótica y de Periodismo se convierten en apoyos para desarrollar la lectura, la escritura, la oralidad y la escucha. Es decir, las teorías propias del área, o contenidos disciplinares, se deben tratar en función del desarrollo de esas cuatro habilidades sin descuidar, claro está, la dimensión actitudinal del estudiante en ese proceso formativo.

En el marco del "Sistema nacional de evaluación estandarizada de la educación", el MEN (2014, p. 18) cambió la denominación de Lenguaje por la de Lectura crítica, con el fin de promover y medir la capacidad de los estudiantes para "comprender, interpretar y evaluar" cualquier texto (verbal y no verbal), y estableció tres "competencias básicas" que deben ser desarrolladas en el proceso lector y que, de modo implícito, se corresponden con la teoría de Cassany (2013): lectura de las líneas, entre líneas y detrás de las líneas. Con el cambio de la denominación Lenguaje por la de Lectura crítica, se propone, a mi juicio, una educación que promueva en los estudiantes capacidades para pensar, discernir y desempeñarse de manera autónoma, reflexiva, analítica y crítica en la actual sociedad cambiante, compleja e invadida por el abrumador flujo de información de toda índole. Una educación que priorice el desarrollo de competencias, que involucre el saber interiorizar conocimiento (aprender), pero también el saber ser, hacer, pensar, 
discutir, crear, transformar, resolver problemas, interpretar, aportar, elegir, decidir, asumir posturas argumentadas y convivir.

Ahora bien, en diversos contextos extranjeros y colombianos abundan valiosas investigaciones enfocadas en problemáticas referidas a la lectura crítica, en el caso de Colombia vale la pena citar el reciente trabajo de Alfonso Vargas (2015) intitulado "Literacidad crítica y literacidades digitales: ¿una relación necesaria? (Una aproximación a un marco teórico para la lectura crítica)". Su propósito central fue aportar a un constructo teórico que posibilitara entender las nuevas aristas de la literacidad crítica en la enseñanza de "las prácticas letradas contemporáneas mediadas por las tecnologías digitales" (pp. 139, 158); para ello, analizó las preguntas que se formulan en el componente Lectura crítica de las pruebas "Saber 11, 2014" del MEN y verificó que la dimensión crítica de la lectura en la educación colombiana es un proceso aún incipiente, pues prevalecen los enfoques lingüístico y psicolingüístico y se deja por fuera el sociocultural y crítico. Esta afirmación nos invitó a ir más allá de lo consignado en las Pruebas del MEN y centrar la atención en la voz de los maestros de Humanidades y Lengua Castellana ${ }^{1}$ de la institución INCT $^{2}$ de Tunja -Colombia- para, mediante encuesta, explorar y describir lo que saben sobre lo denominado por algunos estudiosos del lenguaje y por el MEN como Lectura crítica, con el fin de analizar e interpretar esos conocimientos a la luz de referentes teóricos relacionados con este tipo de lectura (Cassany, 2005, 2013; Girón et al., 2007), con escritura (Carlino, 2006; Avendaño, 2013; Parodi, 1999), con pedagogía crítica (Freire, 1989) y con transposición didáctica (Chevallard, 1998), y aportar algunas reflexiones pertinentes.

La investigación es relevante, por cuanto sus resultados develan lo que realmente ocurre en algunos escenarios escolares y ello, posiblemente, promoverá las transformaciones a que haya lugar. A continuación se expone una base teórica; la metodología de investigación; los resultados, análisis y discusión; y las conclusiones.

\section{Fundamentación teórica}

El encuadre teórico de la investigación se apoya básicamente en los siguientes referentes: lectura crítica ${ }^{3}$, escritura ${ }^{4}$, pedagogía crítica y transposición didáctica.

\footnotetext{
Es una asignatura que hace parte de los planes de estudio de la Educación Básica y Media en Colombia.

En adelante usaremos esta abreviatura para ocultar su verdadera identidad.

En este trabajo nos centramos en la lectura crítica del texto verbal.

No es posible hablar de lectura crítica sin aludir al proceso escritural que debe derivar. De acuerdo con Cassany (2013, p. 138),

"Pensar en lo que podemos escribir después de leer nos ayuda a leer".
} 


\subsection{Lectura crítica}

Antes de disertar sobre la lectura crítica, es preciso aludir al pensamiento crítico, entendido por Campos (2007) como el juicio deliberado y autorregulado resultante del análisis, la síntesis, la evaluación, la inferencia y la explicación de consideraciones conceptuales, metodológicas y contextuales; es un proceso indispensable en la práctica investigativa; es una fuerza liberadora en educación y un recurso fundamental y valioso en la vida personal, ciudadana y profesional del individuo. El pensador crítico es generalmente inquisitivo, curioso, bien documentado, inquieto, de mente abierta, flexible, justo en sus valoraciones, prudente al exponer sus juicios, claro en los temas objeto de discusión, presto a reconsiderar y replantear una postura, organizado en asuntos complejos, dispuesto a mirar el problema objeto de solución desde diversas perspectivas y caminos para lograrla, respetuoso de la opinión ajena, diligente en el rastreo de información, relevante y persistente en la búsqueda de resultados. Entonces, de lo anterior se sigue que el estudiante pensador crítico problematiza constantemente el conocimiento, interroga, no pasa por alto nada, está en permanente actitud dialogante con sus docentes, con sus compañeros y, en general, con quienes convive; esa actitud permite lograr transformaciones en el propio sujeto y en la sociedad en la que está inmerso.

En el decir de Cassany (2005), lo crítico ha permeado varias disciplinas a lo largo de los siglos xx y xxi; por ejemplo: la Filosofía crítica, de la Escuela de Frankfurt; la Pedagogía del oprimido, de Paulo Freire; la Pedagogía y el Pensamiento crítico de sus sucesores; los estudios y las reflexiones sobre la Cultura, de Foucault; los avances recientes sobre el Análisis Crítico del Discurso, de Van Dijk y otros; y las indagaciones sobre la Nueva literacidad, de Aliagas. Con Paulo Freire (1989), la literacidad crítica es una herramienta fundamental para vivir en comunidad que se caracteriza por posicionar al estudiante en el centro del proceso lector.

A propósito de este proceso, Cassany (2013, p. 21), citando a Zavala (2002), recuerda que «No hay una manera "esencial" o "natural" de leer y escribir [...] los significados y las prácticas letradas son el producto de la cultura, la historia y los discursos»; así que, es necesario leer desde la comunidad, pues no basta con descodificar el texto de modo literal e interpretarlo (a través de distintas habilidades cognitivas: saberes previos, inferencias, asociaciones, formulación de hipótesis de sentido, etc.), es imperioso tomar en cuenta la dimensión sociocultural, o "formas particulares que adopta la lectura en cada contexto" (p. 23); esto es, de acuerdo con los entornos personales, sociales, históricos, culturales e ideológicos tanto del autor como del lector, y con el género discursivo en el que se inscribe cada texto. Y para mostrar la relevancia de esta dimensión sociocultural en 
la lectura, distingue tres concepciones de la comprensión lectora, según cuál se considere que sea el proceso para lograr el significado: lingüística, psicolinguística y sociocultural.

Según la primera, el significado está en el texto, el contenido emerge de la suma del significado de todas sus palabras, frases, conectores, preposiciones, conjunciones, pronombres, oraciones, etc. Por consiguiente, "el significado es único, estable, objetivo e independiente de los lectores y de las condiciones de lectura" (p. 25). Entonces, aprender a leer sería un asunto meramente linguístico, se trataría de interiorizar el léxico de una lengua y su sintaxis (tanto oracional como discursiva). Es decir, se orientaría solo hacia la descodificación del texto.

La segunda concepción plantea que el significado del texto ni reside en las palabras, frases, oraciones, conectores, preposiciones, conjunciones, pronombres, etc. ni es único y estable; puesto que está en la mente del lector, quien lo elabora de acuerdo con sus saberes previos, experiencias de vida, modos de pensar y de sentir, y sus contextos sociales y culturales; por ello, el significado de un texto varía de un lector a otro. Cada lector entiende un texto de manera diferente a como lo entiende otro u otros. Además, el mismo lector obtiene significados distintos de un mismo texto si lo lee en épocas distintas o circunstancias particulares de su vida. De acuerdo con este enfoque psicolingüístico, el acto de leer requiere conocer el aspecto puramente lingüístico del texto, desarrollar capacidades cognitivas propias de la interpretación (aportar saberes anteriores; inferir; formular hipótesis de sentido, verificarlas y reformularlas); es decir, además de descodificar el escrito, el lector descubre múltiples sentidos que subyacen.

La tercera concepción no desconoce que el significado se construye por el conocimiento del código lingüístico presente en el texto y por lo que tiene en su mente el lector, pero enfatiza en otros aspectos olvidados: el significado de los vocablos, expresiones, frases y oraciones y los saberes previos que aporta el lector tienen una procedencia social; el texto no surge de la nada, siempre emerge de otros, de los contextos personales y socioculturales de quien lo crea, de su visión de mundo, de sus propias perspectivas, de sus ideologías, creencias y sentimientos; texto, autor y lector tampoco son entes aislados, detrás de cada uno de ellos se ocultan unos contextos determinados, los tres se imbrican en un proceso de lectura.

Para el enfoque sociocultural, leer no solamente es un proceso psicobiológico tratado con unidades lingüísticas y capacidades mentales, es además una práctica cultural inmersa en una sociedad particular poseedora de una tradición, una historia, unas costumbres y unas formas de comunicación peculiares. Leer exige conocer esas características de la comunidad en donde se gesta el texto; no es suficiente con descodificar los registros 
linguísticos o realizar inferencias, es necesario, entre otras acciones, identificar los contextos del autor: dónde y cuándo nació, cuál es su formación académica, a qué cultura pertenece, cuál es su ideología -política, filosófica, religiosa-, cómo valora la sociedad al autor; y conocer la superestructura de cada género discursivo en el ámbito de las diversas disciplinas. Sintetizando, en todo proceso de lectura crítica deben estar presentes los tres enfoques aquí esbozados: lingüístico, psicolingüístico y sociocultural.

Cassany advierte que el lector contemporáneo tiene que aprender a afinar su sentido crítico y ello se logra con actitud investigadora, cuestionando las intenciones, los propósitos, los intereses y los condicionantes de cada mensaje; la lectura crítica es la que asume que el discurso no revela la realidad con objetividad, sino una mirada singular y situada, el saber que propone no es verdad absoluta e inobjetable, pues solo refleja un punto de vista. El lector debe evaluar el discurso desde su propia posición, aceptar lo que le agrade, desechar lo que no y proponer otras alternativas. El conocimiento que vehicula el discurso y la interpretación que se logra dependen de la cultura tanto del autor como del lector. Aquí consideramos que, además, para leer críticamente es indispensable contar con la motivación -deseo de leer, de aprender y de descubrir lo nuevo-, la voluntad propia, la concentración, la atención y unos propósitos claros. Ahora se expone las tres competencias de lectura crítica ${ }^{5}$ propuestas por el MEN (2014); pero de manera complementada, puesto que, como ya se mencionó en la Introducción, de acuerdo con la investigación de Vargas (2015, p. 158), las preguntas correspondientes al componente de Lectura crítica formuladas por el MEN no revelan el enfoque "sociocultural y crítico":

Primera dimensión. Consiste en identificar y comprender contenidos explícitos, tiene que ver con el primer encuentro con un texto; de aquí deben surgir los siguientes procesos que permiten reconstruir su macroestructura (Van Dijk, 1983):

a) Entender, en el ámbito temático de un texto verbal, el significado de las palabras, expresiones, frases, oraciones, enunciados, versos; se tiene en cuenta su función semántica en ese contexto; esto es, de acuerdo con el sentido global del texto objeto de lectura.

b) Dar cuenta del contenido que se explicita en el texto (de lo que se dice o se informa); para ello se emplea la síntesis, a partir de estrategias variadas; entre otras:

- Parafraseo: expresar con palabras propias, y de manera resumida, la información explícita del texto.

5 En este trabajo las denominamos dimensiones de la lectura crítica en concordancia con Girón et al. (2007). Es posible explorarlas tanto en textos verbales como en los no verbales (icónicos, iconoverbales, audiovisuales, etc.). 
- Mapa conceptual: representar en un esquema la información relevante; se elabora a partir de conceptos mediante palabras clave, empleando conectores $\mathrm{u}$ otro tipo de expresiones que permitan articular las ideas fundamentales.

- Diagrama: elaborar un organizador gráfico que condense y muestre la información de manera ordenada, clara, precisa y con poco discurso verbal.

- Ideario: construir un listado de ideas medulares, expresadas en enunciados breves y siguiendo la ilación semántica, o conexión de las ideas y partes que conforman el texto.

Esta primera dimensión corresponde a la lectura literal, qué dice explícitamente el texto; es un ejercicio concebido por Cassany (2013) como lectura de las líneas. Es oportuno insistir en que si el estudiante no ha captado la información que explicita el texto, no logrará hacer inferencias; es decir, incursionar en procesos interpretativos.

Segunda dimensión. Alude al hecho de comprender la manera como se articulan los elementos del texto para construir su sentido global. En la medida en que el lector capture el contenido explícito del texto, descubrirá sentidos ocultos mediante procesos cognitivos: inferencias, asociaciones, analogías, comparaciones, recontextualizaciones, etc. En otros términos, develará lo que no se dice, pero que se sobreentiende. Aquí es menester que el lector identifique y comprenda cómo se relacionan semántica y formalmente los elementos locales que constituyen el texto; por tanto, tendrá que:

a) Reconocer los componentes que estructuran el texto verbal (título, párrafos, secciones, capítulos, partes, estrofas, versos, introducción, desarrollo, conclusiones) y, con ello, identificar el género discursivo.

b) Descubrir las estrategias discursivas que emplea el autor para exponer su pensamiento, sus ideas o su imaginación (argumentación, exposición, descripción, narración, explicación, información, instrucción, diálogo, otras).

c) Incursionar en acciones de interpretación: inferir la temática central y los temas conexos, la intención o propósito comunicativo del texto, las relaciones de intertextualidad -polifonía de voces que confluyen- o relaciones explícitas o implícitas que guarda con otros discursos; descubrir sentidos que subyacen en el texto, por ejemplo, situaciones problémicas, ideologías, aspectos culturales, históricos, políticos, religiosos, filosóficos, sociales, entre otros; y recontextualizar el texto (relacionarlo con el propio entorno real, personal y sociocultural). Cabe advertir que cada interpretación debe ser argumentada con el mismo texto, pues es imperioso evitar las tergiversaciones del sentido. Como se ve, esta 
segunda dimensión se centra en lo que Cassany (2013) denomina lectura entre líneas. Así que, cuando el lector es capaz de detectar sentidos ocultos de un texto, podrá pensar sobre él, señalar su valor y asumir posturas críticas.

Tercera dimensión. Tiene que ver con el proceso de reflexión y evaluación del texto. Las dos dimensiones anteriores, comprensión del contenido explícito y desentrañamiento del implícito, sin duda, incentivan procesos de reflexión, evaluación y crítica argumentada; es decir, pensar sobre el texto leído, emitir juicios de valor y asumir posturas razonadas. Para tales fines, son apropiadas las siguientes acciones:

a) Conocer los contextos personales y socioculturales del autor.

b) Identificar estrategias de argumentación empleadas por el autor, entre otras posibles: asociación; comparación; analogía; ejemplificación; aplicación de principios de otras disciplinas; empleo de criterios de autoridad -citación-; opinión generalizada; comprobación; presentación de datos y evidencias; justificación con base en creencias, vivencias personales, testimonios, imaginarios colectivos y saberes populares de una cultura.

c) Reconocer el punto de vista, o actitud, del autor frente al tema que desarrolla; verbigracia: informa; critica; satiriza; emplea el sarcasmo, el doble sentido, la parodia 0 el discurso ajeno; todo ello con miras a descubrir cómo funcionan esas actitudes y, así, entender y criticar su significado.

d) Asumir posturas críticas argumentadas frente a la manera como el autor concibe y trata el tema o el problema y, en consecuencia, proponer sin descalificar (crítica propositiva).

e) Conocer y analizar las interpretaciones y posturas críticas de otros lectores acerca del mismo texto para compararlas con las propias.

f) Evaluar el texto en sus dos elementos básicos:

- Conceptual: características de la temática -relevante, pertinente, novedosa, atractiva, trillada, obsoleta, controversial-.

- Formal: aspectos lingǘsticos (tipo de lenguaje -especializado, técnico, arcaico, claro, conciso, rebuscado, sencillo, figurado, poético-); aspectos discursivos (estructura de los elementos que conforman el texto; estrategias predominantes, combinación de lo verbal con lo no verbal, etc.). Es claro que 
esta tercera dimensión de la lectura crítica alude, con Cassany (2013), a la lectura detrás de las líneas.

Recapitulando, para lograr una lectura crítica es indispensable leer las líneas, entre líneas y detrás de las líneas; estos tres procesos guardan coherencia con la necesaria convergencia de los enfoques Lingüístico, Psicolingüístico y Sociocultural ${ }^{6}$. Es supremamente importante advertir que, las tres dimensiones de lectura crítica expuestas ocurren de manera simultánea en la mente del lector: en el momento en el que capta la información explícita, es capaz, de acuerdo con sus capacidades cognitivas, de develar sentidos ocultos, que emergen también de las circunstancias socioculturales del autor y del lector, y todo ello le permite reflexionar sobre lo leído, evaluar el texto y asumir posturas. Aquí se presentaron de modo lineal solo por orientación didáctica, pero su exploración en el aula de clase dependerá de la iniciativa de cada maestro, por cuanto coincidimos con Girón et al. $(2007$, pp. 46, 48) en que la lectura crítica "carece de fórmulas y esquemas previos", eso sí, implica un ejercicio constante, una actitud y un compromiso consigo mismo y con el mundo. Además, "se requiere para pensar a partir de la multiplicidad de géneros discursivos, saberes especializados, lenguajes y códigos en función de una cultura de la responsabilidad social y la investigación".

\subsection{Escritura}

El proceso de construcción de significados es esencial para el desarrollo del pensamiento, ya que cuando se escribe y se lee, se piensa; y cuando se piensa, se desarrolla la habilidad crítica del individuo, y su capacidad intelectual se afianza (Parodi, 1999). En el decir de Cassany (2013, p. 138), leer es escribir, "pensar en lo que podemos escribir después de leer nos ayuda a leer. Leer y escribir son una pareja de baile [...] Carece de sentido leer o escribir si no sirve para nada", pues es relevante reaccionar por escrito después de leer un texto. Aduce que el mejor método para formar lectores críticos es la escritura porque ella brinda elementos que ayudan a comprender mejor cómo funciona el lenguaje, el estilo con el que lo usan distintas personas y comunidades para sus propósitos, y las motivaciones que se ocultan tras ese uso. Por su parte, Carlino (2006, p. 10) asegura que "escribir es una de las mejores estrategias para pensar; por ello, se convierte en un instrumento semiótico que cambia las condiciones de trabajo mental", y añadimos: escribir ayuda a aprender, se aprende a leer escribiendo y a escribir, leyendo.

6 Además, con los niveles literal, inferencial y crítico-intertextual propuestos hace algún tiempo por Fabio Jurado, Guillermo Bustamante y Mauricio Pérez (1998). 
Comprendemos que lectura y escritura son dos procesos de pensamiento diferentes, pero mantienen una estrecha relación de interdependencia, el uno no puede existir sin el otro, se escribe para que alguien lea, se lee lo que está escrito, y, generalmente, se lee para escribir lo propio. No cabe duda de que están relacionados, es evidente que tienen en común, entre otros, los siguientes elementos: el uso de saberes previos, la incorporación de estructuras superficiales y profundas, y el conocimiento de aspectos lingüísticos y discursivos. La escritura es considerada como una de las competencias básicas que debe desarrollar todo estudiante y todo profesional. Aquí la entendemos como un proceso mental complejo de producción de sentido en donde se configura la realidad mediante la puesta en juego de saberes, inferencias, argumentos, propuestas, visiones de mundo, experiencias de vida, imaginarios, creencias, intencionalidades, ideologías, sentimientos y dominio del código lingüístico y de los procedimientos discursivos; en el proceso escritural confluyen necesariamente factores cognitivos, actitudinales, socioculturales, lingüísticos y textuales. En el marco de su didactización en el aula, presentamos cuatro acciones concretas que requiere el ejercicio escritural' :

- Planeación: consultar fuentes para documentarse; capturar ideas; elaborar un plan textual (ordenación tentativa de ideas principales, capítulos, subcapítulos, o temas y subtemas mediante esquemas, tablas de contenido, mapas conceptuales).

- Ejecución: escribir, desarrollar cada uno de los elementos contemplados en el plan textual, generar el primer borrador.

- Revisión: ajustar esa primera versión a la convencionalidad de la escritura. Abarca tres fases: autorrevisión, correvisión y heterorrevisión. La primera es un ejercicio que todo escritor realiza varias veces, aquí él se convierte en el primer lector de su propio texto; se sugiere tener un propósito claro de revisión: el contenido (desarrollo temático y coherencia) o los aspectos de forma (procedimientos gramaticales -sintácticos, léxicos, ortográficos- y ortotipográficos), no es recomendable revisar de modo simultáneo esos dos elementos del texto. Esta primera fase arroja una versión que es sometida a un proceso de correvisión, a través de pares (los estudiantes intercambian sus escritos para lograr otra revisión, pero desde una mirada externa); cabe advertir que esta segunda fase debe estar guiada y apoyada por el docente. Los resultados de las dos fases anteriores derivan la elaboración de otra versión

7 Retomamos algunos subprocesos apoyados en modelos cognitivos de la escritura (Flower \& Hayes, 1980). 
que se entrega al maestro para que la revise y la devuelva con un feedback; esta heterorrevisión contribuirá al mejoramiento del texto (Avendaño, 2013).

- Edición: corregir, depurar (sopesando las observaciones del profesor) y presentar una versión final. Este texto constituye el producto para socializar o publicar.

Es legítimo y necesario salir de cualquier fase en un momento determinado de la escritura del texto, para trabajar en otra u otras; por ejemplo, para modificar el plan textual formulado inicialmente, pues este nunca será un derrotero inamovible.

\subsection{Pedagogía crítica}

Indudablemente, la pedagogía revive en las instituciones educativas cuando los maestros reflexionan sobre su quehacer docente, analizan, discuten, emiten juicios valorativos y resignifican conceptos. En este ejercicio, según comenta Vasco (citado en MEN, 2013 , p. 33), el docente pone en juego "un conjunto de conocimientos, disposiciones y habilidades (cognitivas, socioafectivas y comunicativas) relacionadas entre sí para facilitar el desempeño flexible y con sentido de una actividad en contextos relativamente nuevos y retadores, que implica conocer, ser y saber hacer". En virtud de lo anterior, el maestro tendrá que decidir desde qué enfoque o enfoques pedagógicos abordará las prácticas de lectura crítica y del proceso escritural que necesariamente debe derivar. Proponemos aquí para tal propósito, la aplicación de algunos principios de la Pedagogía crítica:

Freire (1989) señala que contra la escuela que reproduce el orden establecido y domestica a los individuos, se ofrece una educación que rompa la cultura del silencio y permita a los oprimidos tomar conciencia de las causas de su situación; para él, la Pedagogía crítica asume el conocimiento como fuente de liberación. Las metodologías propuestas por Freire parten de la realidad y de los saberes previos con los que cuenta el estudiante; de la problematización del conocimiento, es decir, el maestro debe plantearle problemas significativos y relevantes para que los resuelva; de la invitación a que reconozca los hechos históricos que han generado la desigualdad y animarlo para que contribuya a transformar esa realidad; del diálogo permanente como método básico; y de la elección del lenguaje como objeto central de estudio. Consideramos que en el marco de estos principios pedagógicos prevalece en el aula la interacción comunicativa, entendida como una serie de acciones en las que varias personas se ven involucradas alternativa o simultáneamente como agentes, se concreta en lo que comúnmente llamamos conversación, o el diálogo (Van Dijk, 1983), en donde el estudiante es el centro del proceso académico y el profesor, un guía, provocador, dinamizador, cuestionador e investigador permanente. 
Con esta pedagogía se promueve el pensamiento crítico que, como ya se comentó, busca, entre otros logros, fortalecer la responsabilidad en las ideas propias, el intercambio libre de opiniones, la argumentación razonada, el respeto por los planteamientos ajenos así no se compartan, la tolerancia y el autocontrol frente a las críticas (madurez emocional). Dicho enfoque pedagógico, concebido así, se convierte en un pilar fundamental para estimular la lectura crítica, pues contribuye a la formación de un lector capaz de comprender el contenido explícito y el implícito de cualquier tipo de texto, de analizar, de reflexionar, de evaluar, de asumir posturas y discutirlas con argumentos, de sugerir alternativas y actuar para resolver problemas de diversa índole, de reaccionar ante lo leído y de plasmar en textos escritos sus puntos de vista, sus formas de pensar, de sentir y de percibir la realidad.

\subsection{Transposición didáctica}

Sabido es que el docente de Humanidades y Lengua Castellana debe contar con un conocimiento claro de los fundamentos teóricos del lenguaje y de su aplicación didáctica; esto es, dominar los saberes específicos propios de las distintas disciplinas y ciencias que conforman el área, sin desconocer los presupuestos teórico-pedagógicos referidos a los procesos de lectura crítica, escritura, expresión oral y escucha. Para Chevallard (1998), el ejercicio de transformar un saber científico, epistemológico, en un saber para ser enseñado en el aula académica se denomina Transposición didáctica que, en otras palabras, es un fenómeno de pasaje y transformación de un tipo de saber (el científico) a otro tipo de saber (el escolar). La transposición didáctica, en el campo de las ciencias del lenguaje, se manifiesta en la adaptación del saber científico (el de las teorías linguísticas, textolingüísticas, literarias, semióticas, discursivas, comunicativas, lectoras y escriturales), a un saber escolar, básico -que no cambie su esencia semántica-, accesible a los estudiantes.

\section{Metodología de investigación}

Este trabajo se orientó bajo los principios de la investigación aplicada, por cuanto se propuso explorar los conocimientos sobre lectura crítica con los que contaban los docentes de Humanidades y Lengua Castellana, para analizarlos e interpretarlos a la luz de referentes teóricos inherentes a la lectura crítica, la escritura, la pedagogía crítica y la transposición didáctica, y aportar algunas reflexiones que permitan, en un futuro, tomar decisiones para transformar esa realidad educativa. Como ya se informó, la población se ubicó en una institución pública de Tunja (INCT); la muestra se conformó, de modo intencionado, con los 10 docentes del área que laboran en los niveles de Educación Básica Secundaria y Media; la información se recogió a través de una encuesta diseñada con 
preguntas de final abierto y se analizó empleando los enfoques cuantitativo y cualitativo. El procedimiento metodológico abarcó los siguientes tres momentos:

Primero: a raíz del cambio de la denominación Lenguaje por Lectura crítica se inició un proceso de revisión bibliográfica, incluyendo el estudio de los documentos emanados del MEN; se construyó una fundamentación teórica sobre lectura crítica y se incursionó en una aproximación a su aplicación en las aulas de clase de la INCT, a través de los estudiantes de "Práctica I Lengua Materna" de la Escuela de Idiomas de la Universidad Pedagógica y Tecnológica de Colombia, pero en vista de la resistencia de la mayoría de los profesores titulares ${ }^{8}$ de Humanidades y Lengua Castellana, de esa Institución, a que se desarrollaran las clases con el apoyo en ese tipo de lectura, se decidió explorar los conocimientos con los que contaba cada uno de ellos sobre dicho proceso lector.

Segundo: se diseñó la encuesta con cuatro preguntas abiertas, a saber: "¡cómo entiende la lectura crítica?”, "¿cómo dinamiza el proceso de lectura crítica en el contexto del área Humanidades y Lengua Castellana?", "iqué dificultades ha detectado en ese proceso pedagógico?", “¿qué se debe mejorar aún para dinamizar y cualificar el proceso de lectura crítica?". Este instrumento se validó a través de su diligenciamiento por parte de los practicantes ya citados.

Tercero: los mismos practicantes se desplazaron a la Institución Educativa INCT y aplicaron la encuesta a los 10 docentes del área referida. Una vez obtenida la información, se sistematizó, se tabuló y se graficó aplicando el paquete estadístico SPSS (Statistical Package for Social Sciences), para luego abordar los procesos de análisis y discusión

\section{Resultados, análisis y discusión}

Las variables que permitieron sistematizar, tabular y graficar la información recogida fueron: conceptualización de lectura crítica, estrategias pedagógicas para trabajarla, dificultades detectadas en su abordaje y propuestas de los docentes para impulsarla y cualificarla. El análisis de los datos se realizó con el apoyo en las siguientes categorías relacionadas con referentes que constituyen el encuadre teórico de la investigación: enfoques de lectura crítica (lingüístico, psicolingüístico y sociocultural), sus tres dimensiones (de las líneas, entre líneas y detrás de las líneas) y estrategias pedagógico-didácticas para su abordaje (problematización del conocimiento, interacción comunicativa -diálogo en

8 Aquí se denomina 'profesor titular' al docente de Básica Secundaria y Media que labora en una institución educativa pública y que contribuye, de manera mancomunada con los asesores de práctica de la Universidad Pedagógica y Tecnológica de Colombia, a la formación de nuevos licenciados, en este caso, en Idiomas Modernos (español-inglés). 
el aula, discusión contextualizada- e incentivación de reacciones escritas derivadas del proceso lector).

\subsection{Conceptualizaciones de lectura crítica}

Para explorar el conocimiento sobre lectura crítica con el que contaban los docentes de la INCT de Tunja, se consideró indispensable formular una primera pregunta orientada a identificar la concepción que cada uno de ellos tenía sobre este proceso lector. Obsérvense las respuestas en la siguiente figura:

Figura 1. Conceptos de los docentes sobre lectura crítica

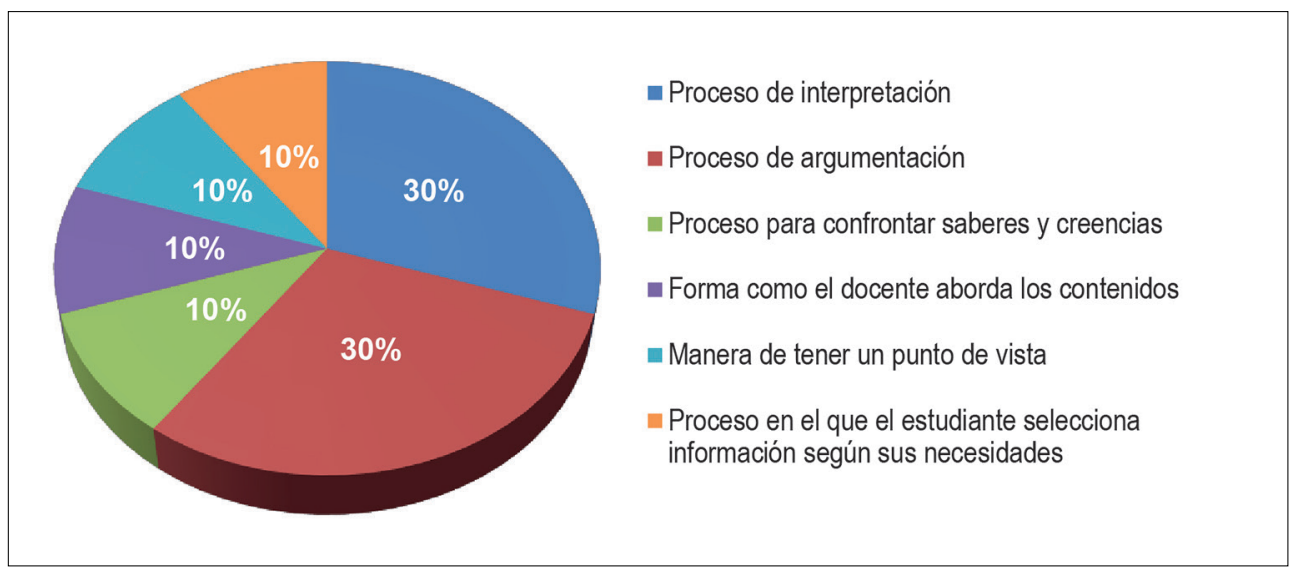

Fuente: elaboración propia ${ }^{9}$

La figura 1 muestra que el 30\% de los profesores concibe la lectura crítica como un proceso de interpretación; y otro 30\%, como un proceso de argumentación. En la primera concepción, el docente asume que si el estudiante descubre contenidos implícitos de lectura: propósitos comunicativos, relaciones de intertextualidad, aspectos sociales, políticos, religiosos, etc. ya está leyendo de manera crítica. Es decir, se conceptualiza la lectura crítica solo como el proceso de leer entre líneas, pero según advirtió Cassany (2013), leer no solamente es un proceso psicobiológico abordado mediante el reconocimiento de las unidades lingüísticas y la capacidad mental del lector (inferencial en este caso, a partir de saberes previos), es además una práctica cultural inmersa en una sociedad particular poseedora de una tradición, una historia, unas costumbres y unas formas de comunicación particulares. Las dos dimensiones de lectura, de las líneas y entre líneas, indiscutiblemente generan la lectura detrás de las líneas, que guiada y acompañada por el

9 Las figuras que aparecen en adelante también son de elaboración propia. 
docente, incentiva procesos de reflexión, evaluación y crítica; esto es, como ya se expuso, pensar sobre el texto leído, valorarlo y asumir posturas argumentadas.

La segunda concepción se desvía hacia el ejercicio argumentativo, si bien este proceso debe implicarse pedagógicamente en el acto lector, no se considera como un concepto de lectura crítica. En las prácticas lectoras sí es imperioso incentivar al estudiante para que fundamente razonadamente inferencias, hipótesis de sentido, reflexiones, análisis, puntos de vista, valoraciones y, sobre todo, su toma de posición.

De la conceptualización "Proceso para confrontar saberes y creencias" (10\%), se infiere que el lector al imbuirse en el texto enfrenta y aporta su bagaje cognitivo a lo expuesto allí para construir el sentido, pero también se deja de lado la dimensión crítica. En la concepción "Forma como el docente aborda los contenidos" (10\%) faltó explicación, ampliación y sustento de esa afirmación. En la respuesta que define la lectura crítica como "Manera de tener un punto de vista" (10\%), se alcanza a vislumbrar una noción acerca de ese proceso, pues el docente insinúa que es un medio que permite configurar en el lector una postura, una perspectiva frente a un tema, y aunque no amplió ni argumentó esa afirmación, piensa que la lectura crítica apunta hacia allá. Y la respuesta "Proceso en el que el estudiante selecciona información según sus necesidades" (10\%) corresponde a un concepto apoyado en el modelo ascendente -botton up- que pone el acento en la información proveniente del texto, simplemente en la extracción de información, descuidando la que el lector le aporta gracias a sus saberes previos y a sus contextos sociales y culturales; se desconoce los procesos inferenciales, reflexivos, analíticos, valorativos y críticos implicados en toda lectura crítica, pues se centra la atención en el enfoque lingüístico que postula que el significado está en el texto.

Desconcierta el hecho de que ningún docente aluda al proceso escritural como ejercicio derivado de la lectura crítica, aquí se ha venido insistiendo que esta debe suscitar la escritura; como ya se mencionó en el encuadre teórico, Cassany (2013) subraya que leer es escribir, "pensar en lo que podemos escribir después de leer nos ayuda a leer" (p. 138) y en esta misma dirección Parodi (1999) considera que cuando se escribe y se lee, se piensa, y cuando se piensa, se desarrolla la habilidad crítica del individuo.

En resumen, prevalecen conceptualizaciones de lectura crítica fragmentadas y algunas desenfocadas. La mayoría de los conceptos se apoyan en el enfoque lingüístico y en el psicolingüístico, y descuidan el sociocultural, lo cual coincide con la conclusión obtenida por Vargas (2015) en su investigación. Indudablemente, esta realidad evidente a través de la voz de los mismos docentes incide en la orientación pedagógico-didáctica de ese tipo de lectura. 


\subsection{Estrategias pedagógicas empleadas para trabajar la lectura crítica}

Como esta es una investigación de corte educativo, fue imposible dejar por fuera una pregunta que indagara por la manera como los docentes de la muestra trabajan la lectura crítica en el aula; en la figura que sigue aparecen sus respuestas:

Figura 2. Estrategias pedagógicas para abordar la lectura crítica

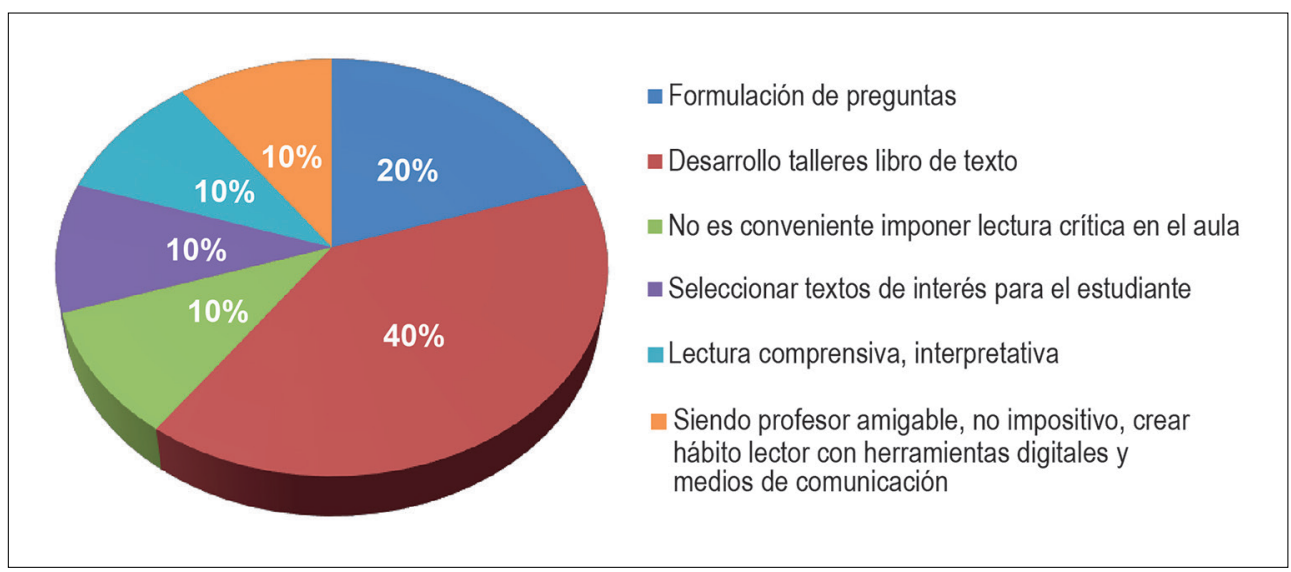

En la figura 2 se observa que el 40\% de los docentes del INCT prefiere la resolución de talleres del libro de texto. La observación directa de clases orientadas así, me permite dar cuenta de ese proceso: los estudiantes copian el "taller" en sus cuadernos, lo desarrollan y, al finalizar el tiempo establecido por horario para la clase, el docente los recoge para su revisión, sin ninguna socialización del trabajo realizado. Entonces, está ausente del aula la interacción comunicativa entre docente-estudiante y estudiantes-estudiantes; no hay diálogo (Van Dijk, 1983), no hay locución ni interlocución, no se acoge postulados fundamentales de la Pedagogía crítica que posicionan al estudiante en el centro del proceso lector (Freire, 1989).

Únicamente el $20 \%$ de los docentes encuestados problematiza el conocimiento para impulsar procesos de lectura crítica, mediante la "Formulación de preguntas", pues intentan romper la cultura del silencio para dar paso a una pedagogía dialogante (Freire, 1989). No obstante, el tipo, calidad y pertinencia de los interrogantes del maestro y la realimentación a las respuestas de los estudiantes determinan el logro de la lectura de las líneas, entre líneas y detrás de las líneas.

Ahora, preocupa esta respuesta: "No es conveniente imponer la lectura crítica en el aula" (10\%), por cuanto el docente no defendió esta postura, lo que impidió analizarla, discutirla y sopesarla. Otro profesor considera la selección de los textos como un factor 
relevante para dinamizar la lectura crítica $(10 \%)$; sin duda su posición es válida, puesto que de eso depende, entre otros factores, la motivación del estudiante y su desempeño lector. Son diversas las variables que inciden en esa escogencia, entre otras: la edad de los estudiantes; sus contextos familiares, sociales y culturales; el género discursivo; sus intereses y la extensión del texto (se aconseja el texto breve para trabajar en el aula). Es de señalar, que los textos seleccionados por el maestro pueden ser de interés para los estudiantes, pero si no se orienta su lectura desde unos enfoques teóricos, pedagógicos y didácticos pertinentes, claros y precisos, no se obtendrá los resultados esperados.

La respuesta que indica "Lectura comprensiva, interpretativa" (10\%), se centra en la práctica lectora en sí misma, pero no refiere las estrategias didácticas que se emplean para trabajarla en el aula. Por su parte, la estrategia centrada en la actitud amistosa y no impositiva del maestro (10\%) es pertinente en la medida en que influye favorablemente en el aprendizaje; la confianza que inspira el maestro y la autonomía que se otorga al estudiante propician el desarrollo de competencias, entre ellas la lectura crítica. De otro lado, el mismo docente sugiere el uso de recursos didácticos de tipo digital, sin duda, ellos atraen mucho más la atención de los estudiantes; sin embargo, si no se hace un uso adecuado y articulado a los procesos de lectura crítica y de escritura, de poco servirán.

En síntesis, la mayoría de los docentes encuestados no tiene claro desde qué enfoque o enfoques pedagógicos trabajan el proceso lector; inferimos que es limitado el conocimiento de referentes teóricos sobre este campo, que pudieran ser didactizados en el aula (Chevallard, 1998), dado que un porcentaje significativo de docentes se ciñe estrictamente a lo que indica el libro de texto. No obstante, cabe aclarar que esta herramienta didáctica es valiosa, el inconveniente está en la manera como se maneja en el aula ${ }^{10}$. Se observó nuevamente que ningún docente aludió aquí a la incentivación de reacciones escritas frente a lo leído.

\subsection{Dificultades halladas por los docentes en el trabajo pedagógico con la lectura crítica}

En los procesos de enseñanza y aprendizaje, surgen problemáticas que el maestro debe enfrentar y analizar para hallar las soluciones correspondientes; por tal razón, se indagó sobre las diversas dificultades que posiblemente influyen en las prácticas de

10 Cuando se decide trabajar una asignatura con el apoyo en texto guía, es menester elegirlo muy bien, comparando opciones y evaluando detallada y rigurosamente cada una. Hecha la elección del libro de texto, el maestro debe adaptarlo, complementarlo con sus propios saberes e idear estrategias pedagógicas y didácticas eficaces que propendan hacia la mejora de los procesos de aprendizaje de sus estudiantes. 
lectura crítica; al respecto, los profesores indicaron, refiriéndose a los estudiantes, las que aparecen en la siguiente figura:

Figura 3. Problemas que afrontan los docentes en el abordaje de la lectura crítica

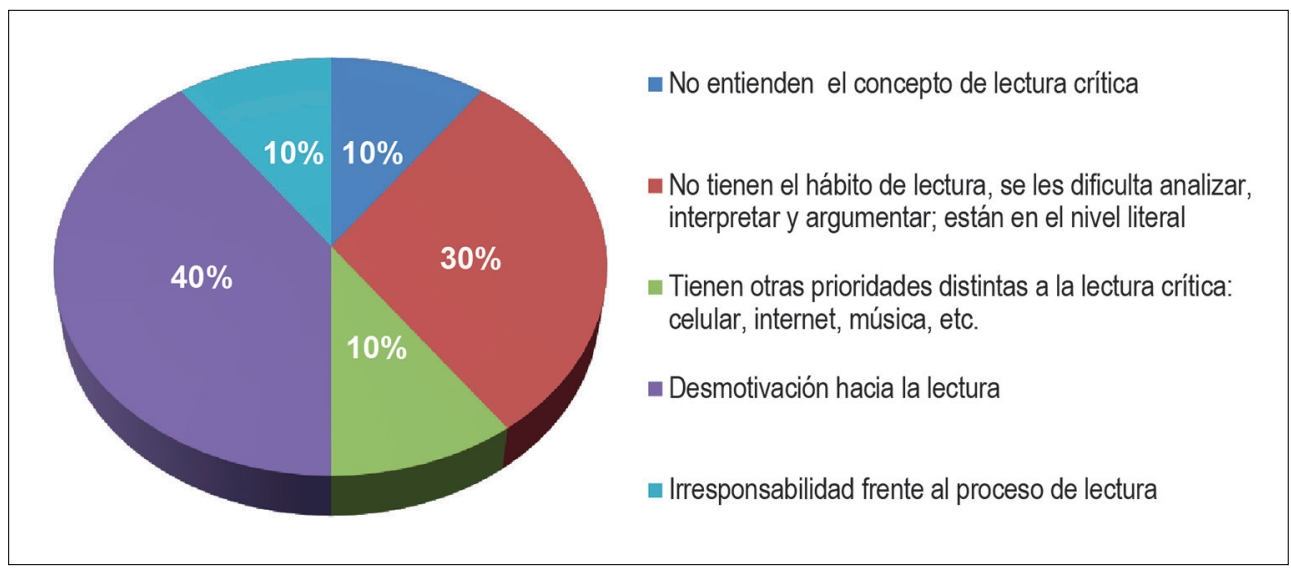

Como se puede ver, los profesores se centran en señalar al estudiante como el único generador de la dificultad para abordar la lectura crítica en el aula. Olvidan que en el proceso de enseñanza y aprendizaje convergen diversos actores (el estudiante, el docente, los directivos, el psico-orientador, los padres de familia) y circunstancias personales, familiares, sociales y culturales. Tanto los actores como las circunstancias que rodean el acto pedagógico influyen en el logro de los propósitos de formación que traza la institución educativa y el Estado.

La mayor preocupación del 40\% de los docentes radica en la desmotivación de los estudiantes hacia la lectura, esta apreciación constituye ya un lugar común en Colombia y en otros países del mundo y, me atrevería a decir, que se convierte en una disculpa. Así que, es urgente indagar sobre las causas de ese desinterés (que probablemente son diversas) para emprender acciones pedagógico-didácticas que permitan estimularla hasta lograr su disfrute y, con ello, el esperado hábito lector que se conseguirá con el ejercicio permanente de lectura, con la voluntad y el compromiso consigo mismo y con el entorno (Girón et al., 2007), pues el no hábito fue otra dificultad declarada por el $30 \%$ de los docentes de la INCT. Les preocupa también que los estudiantes no superen el "nivel literal", este dato concuerda con lo observado directamente en las aulas y con los resultados de investigaciones adelantadas por el MEN (2015-2016) ${ }^{11}$. Dicha deficiencia

11 Consultar http://www.mineducacion.gov.co/1621/article-87176.html. 
requiere atención; es necesario investigar al respecto, idear, diseñar y poner a prueba diversas estrategias para trabajar en el aula y fuera de ella.

Otra dificultad expresada por los docentes tiene que ver con la prioridad que los estudiantes conceden a la internet, al teléfono celular y a la música (10\%), ello no puede ser visto como problema, sino como una oportunidad, pues es conveniente aprovechar esos recursos multimediales y multimodales en los procesos lectores; Vargas (2015), citando a Cassany (2012), recalca que el discurso ya no solo contiene letras, también tiene fotografías, imágenes, videos, audio, reproducción virtual; es decir, el texto adopta un carácter multimedial y/o multimodal. De modo que no es conveniente satanizar estos tipos de texto, puesto que su uso en el aula podría ser un paliativo para la "Desmotivación hacia la lectura" y para la "Irresponsabilidad" frente a esta práctica referida por el 10\% de los docentes.

Ahora, la respuesta "No entienden el concepto de lectura crítica" (10\%) refleja el énfasis puesto en la formación por contenidos y no por competencias, se infiere de esa apreciación que el docente considera suficiente la interiorización de conceptos así no se apliquen en prácticas concretas, de lectura crítica en este caso.

En suma, las dificultades halladas por los profesores en el abordaje pedagógico de la lectura crítica no se pueden atribuir solo al desempeño de los alumnos. Al docente le corresponde: conocer más a sus estudiantes, identificar sus expectativas, sus contextos personales, familiares y socioculturales; autoevaluarse; tomar conciencia de su propio rol y adoptar los cambios y acciones que considere necesarios; reflexionar sobre cada una de las dificultades, analizarlas e investigar las posibles causas, para, una vez detectadas, implementar acciones de mejoramiento; no puede olvidar que su labor docente debe estar articulada permanentemente a la investigación, ello propicia la cualificación de sus prácticas pedagógicas y, por ende, el aprendizaje de sus estudiantes. Como se planteó en el marco teórico de este trabajo, el maestro debe reflexionar diariamente sobre su quehacer docente, analizar, discutir, emitir juicios valorativos y resignificar conceptos recurriendo a sus saberes disciplinares, pedagógicos, didácticos, investigativos y a sus actitudes socioafectivas y comunicativas, en pos de lograr un desempeño eficiente que contribuya al mejoramiento de la calidad de la educación (Vasco, citado en MEN, 2013).

\subsection{Sugerencias de los docentes para impulsar y cualificar la lectura crítica}

Para los fines de esta investigación, se consideró valioso conocer de viva voz de los docentes sus propuestas para movilizar, potenciar y mejorar el proceso de lectura crítica en los estudiantes; veámoslas en la siguiente figura: 
Figura 4. Aportaciones pedagógicas de los docentes

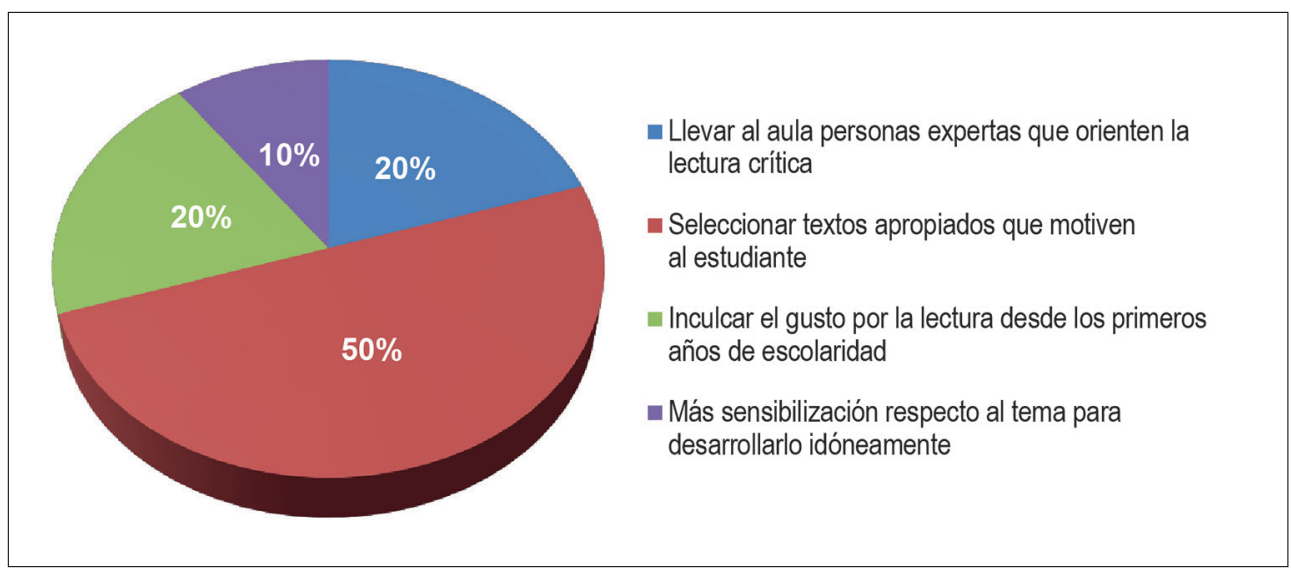

La figura 4 indica que el $50 \%$ de los profesores encuestados propone, para promover y cualificar la lectura crítica, la selección apropiada de los textos; si bien, como ya se comentó, ello es válido, también es cierto que no es suficiente si no se orienta su lectura de modo crítico; es decir, desde los enfoques lingüístico, psicolingüístico y sociocultural a través del ejercicio de las tres dimensiones ya explicitadas (lectura de las líneas, entre líneas y detrás de las líneas). El 20\% sugiere despertar el gusto por la lectura desde los primeros años de escolaridad, eso debería ser así, pero esta postura puede convertirse en una excusa para no asumir la solución del problema. Otro $20 \%$ propone que se lleven al aula "personas expertas que orienten la lectura crítica" y un 10\% solicita "Más sensibilización respecto al tema para desarrollarlo idóneamente". Estas dos respuestas, sinceras por cierto, unidas a varias de las que se han analizado aquí, revelan de nuevo el desconocimiento epistemológico y pedagógico-didáctico en lo que a la lectura crítica se refiere.

De las anteriores respuestas se colige que si bien los docentes reconocen que es necesario impulsar y cualificar el proceso de lectura crítica de los estudiantes, sus propuestas no consideran la problemática de manera integrada, esto es, tomando en cuenta los enfoques lingüístico, psicolingüístico y sociocultural, la lectura de las líneas, entre líneas y detrás de las líneas, la escritura, la oralidad (interacción comunicativa en el aula $)^{12}$, otros agentes y factores o circunstancias diversas asociadas al acto pedagógico.

12 Inherente a la Pedagogía crítica que, según Freire (1989), privilegia el diálogo, la conversación, el no silencio. 


\section{Conclusiones}

El análisis e interpretación de los datos se apoyó en tres categorías enmarcadas en los referentes que constituyen la fundamentación teórica de la investigación: enfoques de lectura crítica (linguístico, psicolingüístico y sociocultural), sus tres dimensiones (de las líneas, entre líneas y detrás de las líneas) y estrategias pedagógico-didácticas para abordarla (problematización del conocimiento, interacción comunicativa, -diálogo en el aula, discusión contextualizada- e incentivación de reacciones escritas derivadas del proceso lector). Se pudo identificar lo que saben los docentes de la muestra sobre lectura crítica, así: la mayoría la conciben de modo parcial y, en algunos casos, desenfocado, puesto que aluden a prácticas interpretativas, a prácticas argumentativas y descartan los procesos reflexivos, evaluativos, críticos y el ejercicio escritural derivado; respecto de los enfoques de lectura, es evidente el privilegio del lingüístico y el psicolingüístico, y la exclusión del sociocultural, lo que concuerda con lo concluido previamente por Vargas (2015) a partir del análisis de las preguntas que constituyen el componente Lectura crítica de las "Pruebas Saber-2014" del MEN.

Prevalece el desarrollo de talleres tomados textualmente del libro guía y sin ninguna puesta en común del trabajo de los estudiantes; ello muestra el desconocimiento también de enfoques pedagógicos que orienten el abordaje eficaz de este tipo de lectura. Los docentes consideran a los estudiantes como los generadores de las dificultades para trabajarla, pues se omite la incidencia en el proceso de enseñanza y aprendizaje de otros agentes educativos, entre ellos el mismo maestro, y de factores relacionados con situaciones personales y socioculturales del estudiante. Para dinamizar y mejorar las prácticas de lectura crítica los profesores presentan propuestas en las que se excluye la interacción comunicativa, la escritura y, como ya se refirió, el rol de los distintos actores y las diversas circunstancias que rodean todo proceso educativo. Es evidente, en algunas respuestas, la necesidad sentida de actualización y cualificación en lectura crítica.

Finalmente, se reitera que los resultados muestran el limitado conocimiento teórico y pedagógico con el que cuentan los profesores de Humanidades y Lengua Castellana de la INCT de Tunja, para trabajar la lectura crítica, lo cual requiere impartir la cualificación respectiva. La voz de los 10 docentes permitió desarrollar esta investigación que constituye un aporte informativo, reflexivo y propositivo, pues los hallazgos dejan al descubierto un problema educativo por resolver. Baste decir por ahora que queda abierta la posibilidad para que un ejercicio investigativo similar a este se realice con los docentes de otras instituciones educativas de Tunja, de Boyacá y del resto del país; sus resultados podrían incitar la toma de decisiones de los estamentos gubernamentales correspondientes; por 
ejemplo, que en primer lugar, el MEN revise sus instrumentos de evaluación del componente Lectura crítica y, luego, ofrezca la cualificación correspondiente a los docentes.

\section{Referencias bibliográficas}

Avendaño de B., G. (2013). ¿Es el buen lector un buen escritor? Ponencia presentada en el Congreso Internacional Lectura y escritura en la sociedad global. Barranquilla: Universidad del Norte, 12, 13 y 14 de junio.

Campos, A. (2007). Pensamiento crítico. Técnicas para su desarrollo. Bogotá: Colección Aula Abierta Magisterio.

Carlino, P. (2006). La escritura en la investigación. Buenos Aires: Universidad de San Andrés.

Cassany, D. (2005). Los significados de la comprensión crítica. Lectura y vida, 26, pp. 32-45. Argentina: Universidad de La Plata.

Cassany, D. (2012). En línea. Leer y escribir en la red. Barcelona: Anagrama.

Cassany, D. (2013). Tras las líneas. Sobre la lectura contemporánea. Barcelona: Anagrama.

Chevallard, Y. (1998). La transposición didáctica. Del saber sabio al saber enseñado. Buenos Aires: Aique.

Flower \& Hayes (1980). The dynamics of composing: Making plans and juggling constraints. En L.W, Gregg \& E., R.Steimberg (Eds.). Cognitive processes in writing. Hillsdale, N.J.: Lawrence Earlbaum Associates.Inc.

Freire, P. (1989). La educación como práctica de la libertad. Madrid: Siglo XXI editores.

García León, D.L. (2014). Minorías lingüísticas en Colombia. Acercamiento desde las políticas públicas y los derechos humanos. Cuadernos de Lingüistica Hispánica, (24), 163-182. doi: https://doi.org/10.19053/0121053X.2765

Girón, S. et al. (2007). ¿Cómo hacer lectura crítica? Colección Cuadernillos Serie Gramática. Bogotá: Universidad Sergio Arboleda.

Jurado, F. et al. (1998). Juguemos a interpretar. Evaluación de competencias en lectura y escritura. Santafé de Bogotá: Plaza \& Janés.

Ministerio de Educación Nacional de Colombia (2013). Documento guía: evaluación por competencias. Docente de básica secundaria y mediaHumanidades y Lengua Castellana. Bogotá. 
Ministerio de Educación Nacional de Colombia (2014). Sistema nacional de evaluación estandarizada de la educación. Alineación del examen SABER 11. Lineamientos generales 2014-2. Bogotá.

Parodi, G. (1999). Conexiones entre comprensión y producción de textos escritos: una aproximación psicolingüística. En Parodi, G. (ed.). Discurso, cognición y educación. Ensayos en bonor a Luís A. Gómez Macker, pp. 59-90. Valparaíso: Editorial Universitaria de Valparaíso.

Pinzón Castañeda, R.J. (2014). English teaching through project based learning method, in rural area. Cuadernos de Lingüística Hispánica, (23), 151-170. doi: https://doi.o $\mathrm{rg} / 10.19053 / 0121053 X .2344$

Van Dijk, T. (1983). La ciencia del texto. Barcelona: Paidós.

Vargas, A. (2015). Literacidad crítica y literacidades digiitales: ¿una relación necesaria? (Una aproximación a un marco teórico para la lectura crítica). Folios, (42), 139-160. Bogotá: Universidad Pedagógica Nacional. 